Check for updates

1 Centre for Behaviour Change, University College London, UK

2 Department of Behavioural Science and Health, University College London, UK

Correspondence to: S Michie s.michie@ucl.ac.uk

Cite this as: BMJ 2020;370:m2982 http://dx.doi.org/10.1136/bmj.m2982

Published: 28 July 2020

\section{Behavioural, environmental, social, and systems interventions against covid-19}

\section{These critical interventions should be top not bottom of the covid-19 research agenda}

\author{
Susan Michie, ${ }^{1}$ Robert West ${ }^{2}$
}

Covid-19 has shown the vital importance of human behaviours such as social distancing in controlling pandemics. ${ }^{12}$ The absence of a cure and an effective vaccine has meant that the world has thus far been reliant on changing behaviours to prevent virus transmission. Behaviour is also crucial to the success of public health measures such as test, trace, and isolate and to effective clinical management of cases. If an effective vaccine is developed, behaviour will be crucial to its success because low uptake could be a big problem. ${ }^{3}$

The director general of the World Health Organization recognised the importance of behaviour in comments made on 29 June 2020, in which he stated: "Every individual must understand that they are not helpless-there are things everyone should do to protect themselves and others. Your health is in your hands. That includes physical distancing, hand hygiene, covering coughs, staying home if you feel sick, wearing masks when appropriate, and only sharing information from reliable sources.”4

Behaviours are embedded in complex systems involving individuals, groups, and communities operating in diverse physical and social environments. Large scale behaviour change of the kind required to suppress pandemics requires behavioural, environmental, social, and systems interventions. When these have been applied in areas such as tobacco control, they have had considerable success, saving hundreds of thousands of lives each year across the globe. ${ }^{5}$

These interventions need to be informed by a scientific understanding of the complex processes that influence behaviour. Common sense understanding is not enough and can often lead to interventions that are at best wasteful and at worst counterproductive. In tobacco control an infamous example was acceptance of the common sense idea that "low tar" cigarettes meant low risk. ${ }^{6}$ This was based on a failure to recognise that smoking is primarily a means of ingesting nicotine and that smokers would increase the intensity with which they smoked low tar products to obtain their desired level of nicotine intake.

There are many more such examples in behavioural science, and they are beginning to emerge in the handling of the covid-19 pandemic. For example, the common sense idea of "behavioural fatigue" and concern that locking down too early may lead to widespread non-adherence later, was invoked in the UK for justification of the catastrophic delay of strict social distancing measures in the UK. ${ }^{7}$ Behavioural fatigue was an ill-defined new term that had no basis in behavioural science.

\section{Imbalance}

Failure to recognise the importance of behavioural, environmental, social, and systems research in tackling global health problems is widespread. For non-communicable diseases such as cancer, behaviours contribute to more than $40 \%$ of the incidence ${ }^{8}$ but behavioural prevention accounts for less than $5 \%$ of the research budget. ${ }^{9}$ In the case of covid-19, the almost total dominance of clinical research over behavioural is illustrated by the fact that a recent search found 975 registered and 46 reported drug trials but only six registered and one reported behavioural, environmental, social, or systems intervention trial

(https://www.bessi.net.au/).

The imbalance in resources devoted to clinical versus behavioural intervention research is further compounded by a huge geographical imbalance. Thus $90 \%$ of covid-19 research is being conducted in countries that have around $10 \%$ of the world's population, with most in high income countries. ${ }^{10}$

To get maximum benefit from large scale investment in behavioural research to tackle pandemics it is crucial to have a coordinated programme that can identify and address research gaps and priorities. This requires adoption of appropriate methods and frameworks that capture the hierarchy of actors in the system from individual to community to population ${ }^{11}$ and the full range of interventions that can be effective. ${ }^{12}$ Advances in the application of artificial intelligence to behavioural science can help with this. ${ }^{13} 14$

We currently have little evidence on the effectiveness of behavioural, environmental, social, and systems interventions to tackle covid-19 in different geographical and social contexts or on their mechanisms of action (processes of change). ${ }^{15}$ For example, there is almost no relevant evidence on how to promote adherence to behaviours such as distancing from other people and households, hand cleansing, effective use of face coverings, and avoiding touching one's eyes, nose, or mouth with contaminated hands. Yet these behaviours are absolutely crucial in suppressing transmission, particularly when governments decide that "lockdowns" are not sustainable.

In summary, we urgently need a major coordinated programme of research to develop and evaluate behavioural, environmental, social, and systems interventions (see https://www.bessi.net.au/ for 
information about the emerging BESSI collaboration) that will be effective and viable in tackling the covid-19 and future pandemics. Success in other areas of behaviour change shows that this kind of enterprise can be highly effective and cost effective. It will require research funders, government, and policy makers to recognise the importance of this work and allocate appropriate resources to it, and will require researchers to collaborate across a range of disciplines and countries with varying resources and to deliver their findings efficiently to policy makers.

Competing interests: We have read and understood BMJ policy on declaration of interests and declare we are unpaid directors of the Unlocking Behaviour Change Community Interest Company.

Provenance and peer review: Commissioned; not externally peer reviewed.

1 Flaxman S, Mishra S, Gandy A, etallmperial College COVID-19 Response Team. Estimating the effects of non-pharmaceutical interventions on COVID-19 in Europe. Nature 2020:1-8. doi: 10.1038/s41586-020-2405-7 pmid: 32512579

2 Islam N, Sharp SJ, Chowell G, etal. Physical distancing interventions and incidence of coronavirus disease 2019: natural experiment in 149 countries. BMJ2020;370:m2743. doi: 10.1136/bmj.m2743 pmid: 32669358

3 Just 50\% of Americans plan to get a COVID-19 vaccine. Here's how to win over the rest. Science 2020 Jun. https://www.sciencemag.org/news/2020/06/just-50-americans-plan-get-covid-19vaccine-here-s-how-win-over-rest

4 WHO director-general's opening remarks at the media briefing on covid-19, 29 Jun 2020. https://www.who.int/dg/speeches/detail/who-director-general-s-opening-remarks-at-the-mediabriefing-on-covid-19---29-june-2020

5 Wipfli H, Samet JM. Global economic and health benefits of tobacco control: part 2. Clin Pharmacol Ther 2009;86:272-80. doi: 10.1038/clpt.2009.94 pmid: 19536066

6 Warner KE, Slade J. Low tar, high toll. Am J Public Health 1992;82:17-8. doi: 10.2105/AJPH.82.1.17 pmid: 1536326

7 Why a group of behavioural scientists penned an open letter to the UK government questioning its coronavirus response. Behavioral Scientist2020. https://behavioralscientist.org/why-a-groupof-behavioural-scientists-penned-an-open-letter-to-the-uk-government-questioning-its-coronavirus-response-covid-19-social-distancing/

8 Cancer Research UK. Causes of cancer and reducing your risk. 2015. https://www.cancerresearchuk.org/about-cancer/causes-of-cancer

9 National Cancer Research Institute. Prevention. 2017. https://www.ncri.org.uk/prevention/

10 Lang T. Plug COVID-19 research gaps in detection, prevention and care. Nature 2020;583:333. doi: 10.1038/d41586-020-02004-1 pmid: 32669692

11 Bronfenbrenner U. Toward an experimental ecology of human development. Am Psychol 1977;32:513-31doi: 10.1037/0003-066X.32.7.513

12 Michie S, van Stralen MM, West R. The behaviour change wheel: a new method for characterising and designing behaviour change interventions. Implement Sci 2011;6:42. doi: 10.1186/1748-5908-6-42 pmid: 21513547

13 Michie S, Thomas J, Johnston M, etal. The Human Behaviour-Change Project: harnessing the power of artificial intelligence and machine learning for evidence synthesis and interpretation. Implement Sci2017;12:121. doi: 10.1186/s13012-017-0641-5 pmid: 29047393

14 Michie S, Thomas J, Mac Aonghusa P, etal. The Human Behaviour-Change Project: an artificial intelligence system to answer questions about changing behaviour[version 1; peer review: not peer reviewed]. Wellcome Open Res 2020;5:122.

doi: 10.12688/wellcomeopenres.15900.1. pmid: 32566761

15 West R, Michie S, Rubin GJ, Amlôt R. Applying principles of behaviour change to reduce SARS-CoV-2 transmission. Nat Hum Behav 2020;4:451-9. doi: 10.1038/s41562-020-0887-9 pmid: 32377018

This article is made freely available for use in accordance with BMJ's website terms and conditions for the duration of the covid-19 pandemic or until otherwise determined by BMJ. You may use, download and print the article for any lawful, non-commercial purpose (including text and data mining) provided that all copyright notices and trade marks are retained. 